\title{
AGRICULTURE IN AN INDUSTRIAL FRAMEWORK
}

\author{
Edgar Thomas, Professor-Emeritus ${ }^{1}$ ) \\ University of Reading, England
}

The present shape of agriculture in every country is the result of a complex of past economic, social and political factors. These factors are continuously under pressure from new forces. Today, for better or for worse, the pursuit of economic growth has become the dominant force the world over.

In order to achieve and sustain a more rapid rate of growth two things are necessary. The first is to improve productivity within each activity by the greater application of capital, by better technology, by better management and by better organisation. The second is to aim at the optimum allocation of resources b e t w e e $n$ activities by moving resources from less to more productive uses. Pursuing these two paths towards faster growth is releasing two sets of forces which are exerting a radical impact on both the size and the pattern of agriculture.

This paper deals with this impact on agriculture in contemporary Britain - a highly industrial and a preponderantly urban nation committed to the experiment of running a hybrid economy based on the two pillars of private enterprise and public control.

The massive science-based technical and economic changes now going on in Britain as in other countries are swiftly transforming the agricultural industry into a multi-sector complex. Already four major sectors (each with its own substantial sub-sectors) can be distinguished. These are:

1. f a rming itself continues to be the main sector, but its relative role within the agricultural industry is diminishing;

2. on the in put side there are powerful and expanding chemical, biological, engineering and constructional sectors;

3. on the o u t p u t side there are strong and vigorous distributive and processing sectors;

4. there are also elaborate and extensive financial, legal and administrative sectors.

1) Lecture given at Helsinki University on 29th September 1966. 
Within the farming sector one can foresee a quickening of the bewildering pace at which the findings of science, technology and economics will be applied in practice on the farm. Scientific and economic research is likely to be concentrated more and more on reducing the high incidence of risk and uncertainty peculiar to farming. In particular, scientific advances can be expected to lead to a general improvement in the control of input/output ratios both in animal and in crop production. This improvement will, in turn, depend upon the use of more exacting, precision demanding, technically and organisationally advanced methods throughout farming.

The great boon of progress here will be to help the farmer to approach nearer to the factory manager's ability to forecast his output from a given input. By taking some of the physical "chanciness» out of farming it will be a big step towards control of supply at the farm level.

For its full fruition this and similar advances need to be accompanied by a marked extension of division of labour, both within farming itself and between the farming sector and the non-farming sectors of the industry.

Division of labour within farming is taking many forms - there is increasing specialisation on the individual farm, between groups of farmers and between one farming region and another. In general, the finished products of farming are tending more and more to be the outcome of the shared activities of many farmers who divide the long production cycle between them. There is an analogy here with the trend to segregate in separate establishments the production of components in factory industries. Major farming examples of this trend are the separation of livestock production from crop production, the divorce of animal production from the growing of animal feed, the separation of seed growing from crop production and the separation of animal breeding from the production of livestock products.

Division of labour of this kind not only makes the farmer more of a specialist, it also simplifies his business. This is a big gain, for there is now so much to learn about everything in farming that only the exceptionally gifted farmer can hope to attain high levels of performance in more than one or two branches. Moreover, separating the various links in the long chain of growing the products of farming helps to put farms of different sizes and land of different potential into the uses for which they are best suited. Such a deployment of resources within farming could become one of the most nearly cost-free ways of increasing its productivity.

If the full benefit is to be derived from this division of labour it is imperative that the intra-farm transactions involved should be properly organised. This is, the one aspect of marketing which lies entirely within the control of farmers themselves. At long last farmers in Britain are taking active and exciting steps to organize on the basis of contracts the trade in the goods which they sell to and buy from each other. Almost every week fresh groupings are formed for a variety of purposes - groups for rearing dairy cows on contract, groups for transferring calves from dairy farms for fattening on arable farms, groups for supplying weaner pigs to bacon producers and the like. This kind of development is admirably suited to exploit the diversity of our farming regions. It is also well suited to the diversity of farm sizes which is a feature of our farm structure. 
Equally exciting and equally promising are the many new groupings of farmers for the joint use os labour, machines and expensive installations of many kinds. The aim of these groups is to help the family business to cope with the exacting task of financing the capital intensive farming of today. In a sense they can be considered as a form of voluntary collectivism, for the groups are founded and run entirely by farmers for farmers. The guiding principle of this movement, for it is already a movement, is the belief that by pooling their resources group members gain many of the benefits of scale without serious loss of business sovereignty or independence.

The so-called "syndicates» for the joint ownership and use of machines started in Hampshire in 1955 may be taken as the prototype of the movement. The sharing of labour and machines is no new thing in farming. What is new about the syndicates is that they give good-neighbourliness a modern business look.

As farmers gain experience of this sort of joint action and find that it works and still leaves them their own masters, they are becoming more adventurous and already they are applying the method to all kinds of other activities. They are, indeed, finding that the method is one of the most flexible and adaptable of all the weapons in the armoury of structural change. Its relevance to the problems of investment and the better use of capital is of special significance.

This movement is growing rapidly - the number of machinery syndicates alone has already topped the one thousand mark. It is of interest to note that the leaders are generally the medium and large farmers, often young and well-educated. The movement now has official blessing and the groups qualify for a variety of grants from the state. Moreover, the National Agricultural Advisory Service is shifting its emphasis to assisting members with the many technical and organisational problems which group action at the farm level entails.

Turning to the division of labour between the farming and the non-farming sectors of agriculture we have, at the production end, the many trades and businesses which to-day supply the farmer with his equipment, his raw materials and with services of many kinds.

First, there is the trend for more and more of the manual tasks on farms to be done by people who are not themselves farmers or farmworkers in the conventional sense. For example, in Britain today there are all kinds of contractors prepared to do all kinds of jobs for farmers from milking their cows to harvesting their crops. Every week the farming papers carry whole pages advertising these services. Many erstwhile farm workers are now employees of contractors of this kind. Although these workers have left the farms, they are not lost to agriculture. These developments are changing the structure of the farm labour force and they are well suited to the needs of the one-man and the two-man farms which predominate in Britain. But they are also increasingly used by the large farmers.

The servicing of farmers by outsiders is by no means restricted to manual operations. Of equal importance is the servicing of agriculture by a state-financed research and advisory service. This is agriculture's counterpart to the advantages which other industries enjoy from the expenditure which their big corporations can 
afford on research and on the application of the findings of research to production and marketing.

But technical competence is not enough to ensure success in farming today. That is why the present promotion of business management into a special service of practical use to farmers is so significant. The techniques of planning and budgeting are now applied extensively by both official advisers and by private consultants to help farmers with reorganizing their farms and making the best use of resources. Last year saw the establishment of the Farm Management Association which already claims to have 1,000 members. The response of our farmers to this professional management service has been a revelation, it is the best possible augury for the future efficiency of the industry.

In Britain the servicing of farmers in both technical and management matters is also undertaken by those who staff our marketing boards and commodity commissions. The Sugar Corporation is a good example. It is likely that these bodies will extend their advisory functions by providing a comprehensive service so far as their specific products are concerned.

Lastly, many of the trades which supply farming with machines and raw materials also have well staffed technical field advisory services for their farmer customers. Some of these are also active in the field of management advice. For example, only last month the Ford Motor Company set up a Farm Accounting Computer Service for farmers who use Ford tractors.

Co-operating with these ancillary trades - the machine makers, the fertilizer manufacturers, the seed firms and the feed compounders - enables the farmer to employ, as it were on his own farm, the specialist skills which arise from the economies of scale of the big businesses which supply him with his requisites.

It is also a big step towards the industrialisation of farming itself. Not only is the use of purchased raw materials leading to a decline in the importance of land as a factor of production. It is also rapidly transforming agriculture into one vast industry within which the actual job of farming is only one of many stages.

Today, our farmers are spending nearly one-half of their gross receipts roughly $£ 800$ million a year or about $£ 50$ per farm per week - in payment for the goods and services supplied to them by non-farmers. It is this vast expenditure which accounts for our capital intensive farming. Our farming, in fact, now has a higher investment per man employed than all but two or three of our giant manufacturing industries.

In a recent book on "Europe's Needs and Resources" there is an attempt made to calculate the number of workers who, as employees of these ancillary industries, can be regarded as being associated with agricultural production. For Western Europe as a whole it is shown that for every 100 persons employed on farms there are 28 employed in industries which make equipment and supplies for the operations of farming. But, for the United Kingdom, it is shown that by adding the workers in the supporting industries to those directly engaged on the farm the "real" labour input per acre of farm land is almost doubled.

It is much the same story when we turn to consider what happens when farm 
products leave the farm gate. Here again it is the story of many tasks which farmers used to do themselves now being done for them by people who are not farmers. Once more there is division of labour - this time it is between the farmer and a whole array of interests which now dominate the markets in which he sells.

In Britain, as in other countries, the market for farm products is passing through a spectacular revolution. Direct contact between the farmer and the consumer is almost a thing of the past and few products now reach the housewife in the form in which they leave the farmer. In fact over $60 \%$ of British farm produce undergoes processing in some form or other and about two-thirds of what the housewife spends on food goes to buy processed food. Some 850,000 people now work in our foodprocessing industry which has a turnover of about $£ 460$ in a year. Furthermore, new industrial uses are being continually found for both the food and the non-food products which farmers sell. Last year, for example, British farmers sold over $£ 600 \mathrm{~m}$. worth of "raw materials" for use in the food processing and other industries.

These developments are radically altering the character of the demand for the products of farming. And as a result farmers are changing their status from being sellers of consumer goods to being sellers of producer goods. Already the requirements of processors, retail chains and super markets are of greater immediate relevance to our farmers than are the needs of the housewife. This change in customers is having a profound impact on the structure of the industry.

Amongst other things, the new customers are insisting more and more on forward contracts to ensure a regular throughout of high quality raw material from their farmer suppliers. Producing to contract is fairly common in manufacturing industries and the factory manager gears his production to the entries in his order book. The farmer who can do likewise is well on the way to insure against the danger of producing unsaleable produce.

Many of our farmers - those who grow sugar-beet are a good example have had contracts of this kind for a long time and the practice is spreading. But in farming, production to contract involves formidable technical and management problems. The Americans talk about specification-buying leading to specification - production. And these sophisticated terms convey the essence of the contract system - an undertaking to supply stated quantities of stated quality at stated times. It is infinitely more difficult to do this in farming than it is in manufacturing industry.

But the contract system (not to be confused with "integration") is so important for the next step forward that it almost justifies putting the main emphasis in research and advice in helping farmers to master the intricate problems involved in controlling quality and quantity and in timing the production and marketing of their output. Two things, already emphasised earlier in this paper, can make a powerful contribution to this end. The first is the intensification of research into the basic problem of input/output control on the physical level. The second is maintaining and increasing the impetus towards group action by farmers themselves. 
The growth of the ancillary trades at both ends of the agricultural spectrum has given our farmers many of the benefits of scale both in the supply of requisites and in the disposal of produce. But it has also confronted them with the challenge of new problems.

In particular the economic and financial efficiency of the farming sector now depends largely on what goes on outside that sector in determining the supply and prices of its requisites and products. And this leads to the danger of intimidating concentration of bargaining power against the farmer from monopoly conditions in his factor markets and from monopsony conditions in his product markets.

In this situation the need for countervailing action by farmers themselves is self evident. This is taking many forms, all concerned with mobilising an army of some 400,000 farm businesses to meet the challenge of commercial strength on more equal terms. Some forms are voluntary and some are statutory, some are nation-wide businesses and some are modest local ventures. Co-operatives, marketing boards, marketing corporations, commodity commissions and the vigorous selling and buying groups now springing up provide the evidence that British farmers are fully alive to the need for collective strength even though they may not be agreed on the best way of organising it. It may, indeed, be the case that each and all of these forms have their place in the general strategy of attack, for the problems ahead call for eclectic and not for doctrinaire solutions.

Be that as it may, all these developments add up to a powerful force for shaping the structure of British agriculture today. It would, indeed, be true to say that together they already constitute one distinct sector of the industry's complex structure.

It would be misleading, however, to imply that the main function of these developments is to withstand the mencroachment" of the ancillary industries on the domain of the farmer. Some protective action is clearly called for. But much more important is positive action to exploit to the full the benefits of the sensible division of labour which now exists between farming and the other sectors of the industry. Such dynamic action is concerned not with "stemming the flood" but with channeling it into the drive to increase productivity throughout.

Today, the productivity of the resources allocated to agriculture depends on all those who participate in the production of food regardless of whether they do so directly or indirectly. Some are farmers and farmworkers. Some supply farmers with machines, fuel and oil, feed and seeds, fertilisers and other raw materials. Some are engaged in processing the products which farmers sell into the finished consumer goods which housewives buy. Some cater for the needs of farmers for transport, marketing, credit, accountancy and other commercial services. Some are contractors or technical and managerial advisers and consultants whose job it is to purvey all manner of noff-the-farm" services. The contribution of each and all must be kept in mind in any assessment of the role of the agricultural industry in the general economic growth of the nation.

As stated at the start improving productivity within each industry is only one of two paths which must be followed in the quest for the more rapid growth of the economy in the round. We must turn now from the forces which are concerned 
with the use of resources $\mathrm{w}$ i t h i n industries to those concerned with the optimum allocation of resources be $\mathrm{t} w$ e e $\mathrm{n}$ one industry and another.

For this governments everywhere are resorting more and more to some form of central guidance and control. This means that agricultural policy will not, as so often in the past, be considered in isolation. In future the requirements of agriculture for men, money and other scarce resources are bound to be integrated in a national blueprint for economic growth and development.

This is a major, and, fundamentally, a new general feature of the setting of the industry.

Planning of this kind implies the acceptance by governments of an obligation to ensure harmony between the capital equipment and business structure of agriculture on the one hand and, on the other, explicit year by year, product by product estimates of production needs, together with categorised target figures of agricultural employment. The production requirements will be prepared in the light of the country's external and internal prospects. The employment targets will have regard to socially acceptable inter-industry mobility assumptions, age-spreads and similar considerations.

This new acceptance of planning as a way of regulating affairs so as to attain maximum economic growth with the minimum of social hardship is going to have major implications for the institutional and administrative framework of agriculture in the years ahead.

In particular one can expect a considerably higher degree of formalisation in agricultural institutions. For example, in the farming sectors there will be some form of public corporations charged with the distribution of the main products, extensive delegation to independent agencies and firm by means of conditional licences and wide use of prescriptive contracts in dealing with farmers. Similar and related developments will be necessary in the minput" sectors as well as, and especially in, the fields of finance and credit.

In Britain our planning aims at buttressing rather than replacing the forces of competition. It is carried out in the fullest consultation with each major industry including agriculture, and it depends on persuasion and consent. British planning lies emphasis on three things - on an incomes policy covering all incomes, on special councils for selected industries to throw up sectorial plans and on overall guidance rather than compulsion from central government.

All this is not new for our agriculture which, as a result of our system of price support, has for years differed from other industries in the private sector in having been more directly and continuously affected by official action. Indeed, since the Agriculture Act, 1947 our agricultural policy has, in a sense, been a pilot experiment in this type of planning. Thus our Annual Price Review possesses the three desiderata - it attempts to stabilise the aggregate net income of farming; it provides for consultation between government and farmers; it attempts to guide farm output in conformity with national requirements.

In September 1965 the government published the first National Plan for the United Kingdom. It is a five year plan. And it sets out with reasonable precision the main changes which can be expected in the levels of output and employment 
in each major industry up to 1970 . The programme for agriculture, like other parts of the Plan, is to be kept under constant review to measure the progress being achieved and to assess the resources required. The government and the Farmers Unions have agreed that the Annual Reviews under the 1947 Agriculture Act should be used for this purpose.

The Plan assigns two main tasks to British agriculture. The first is to aid the balance of payments by a programme of selective expansion. The second is to continue to release manpower and other resources to help make good shortages elsewhere.

The Plan estimates that the growth in demand for food due to increases in population and in incomes between 1964 and 1970 will be of the order of $£ 200 \mathrm{~m}$. It has been decided that British agriculture should meet the major part of this expected growth in demand. But it is to do so through a selective expansion programme - stepping up the output of beef, milk and cereals, holding pigs steady and cutting down on eggs.

The real challenge of the Plan to farmers, however, is that agriculture is asked to achieve this expansion in output and at the same time release both labour and land for other purposes. In other words the accent is not only on greater production, it is even more on higher productivity.

Indeed, the major part of the contribution of farming to the fulfilment of the Plan is the projected release of some 140,000 workers by 1970 . This means a drop of about 28,000 a year - not so very different from what has been happening over the last decade and more. Clearly this drain cannot continue indefinitely at this rate without incurring the risk of the underemployment of capital on many farms because of a lack of labour to operate it.

The real significance of the drop in man-power lies, however, in the fact that, up to the present, it has been almost entirely a drop in the ranks of hired workers. In contrast, the drop in the number of farmers has been insignificant. This contrast between the fall in workers and the fall in farmers is making our farming even more outstandingly than before an occupation carried on by "master-men" of self-employed persons. So much so that the bulk of farmers now run their farms without regular hired help whatsoever.

This in turn raises the two big questions of the supposed lack of flexibility and lack of mobility in British farming. And mobility, we are told, especially mobility as between one industry and another is almost a pre-requisite of economic growth and development.

The question of flexibility is linked to the size-structure of farms. There is much talk in Britain today about the need for making farms bigger and improving their lay-out. No one doubts this need. But it is easy to exaggerate the extant to which our farm structure is antiquated. The fact is that, so far, it does seem capable of absorbing technical change without itself undergoing radical alteration in the process. When one examines the statistics of farm sizes one is struck not by the 
evidence of change but by the evidence of stability. There is change certainly farms on the whole are getting bigger.

There are at present some 400,000 farming units in the United Kingdom. An official report on "The Structure of Agriculture" issued recently divides these units into the following four size groups according to their standard labour requirement: - 40,000 large holdings capable of providing full-time work for at least four men; 65,000 medium-sized holdings capable of providing work for from two to four men; 95,000 small holdings capable of providing work for one or two men; 200,000 very small holdings normally not providing full-time work for one man. This classification shows the heterogenous character of our farm structure in the U.K. Three points need to be made about it.

The first is that the group described as large holdings produces about half of the total farm output. There is another estimate which states that we now have about 1,800 farms each producing upwards of $£ 500,000$ worth of food per year and thus accounting for one-tenth of the total output. Nevertheless, the interesting feature is that there is no spectacular increase in the number of these very big farms. Even more interesting is the fact that the very big farms are not themselves getting bigger. Some observeres believe that this situation will change and that the compelling force will be the sharpening of the financial strain on the family business as farming becomes more and more capital intensive. So far less than $3 \%$ of our businesses are in companies, mainly private companies. Up to now few businesses have been big enough to attract investment on the money market. But with inflation, escalating land values and mounting working investment many farms may well reach the stage which will bring them within the purview of public company finance.

In sharp contrast, the second point about the classification is the evidence it gives of the overwhelming numerical importance of small and medium farms in Britain. Together they still account for over $90 \%$ of all holdings and for over $80 \%$ of full-time farms. The reasons for their astonishing power of survival are not ephemeral. There are weighty technical factors which indicate that economies of scale do not apply to farms in the same way as they apply to factories. Moreover, the clubbing together of farmers for group action for more effective production and tor commercial and trading purposes can go far to invest the existing structure with many of the benefits of scale. The fact is there is no optimum size of farm and an industry based exclusively on large farms would be far from efficient in-so-far as it would fail to provide outlets for the wide range of conditions and the variety of managerial talent available.

Thirdly, the classification shows that one-half of all holdings are of a parttime character. There is evidence that in Britain, as in some other advanced countries, part-time farming is on the increase. This is an unexpected but significant phenomenon. The trend is by no means confined to the small farm. On the contrary many of our big and progressive farms are run by people with other business or professional interests. The motives are complex ranging as they do from those who regard the farm as a source of investment to those who treat it as a home and a source of relaxation. With the increase in leisure and transport facilities part-time farming 
of many kinds is likely to do much to soften the harsher acerbities of factory employment and urban living.

It is all too easy to write off the role which part-time farming can play in making full use of resources within the agricultural industry. It should also be remembered that the income of the farmer - full-time as well as part-time - is not necessarily confined to that derived from his farm business. We have no information about the extent to which our farmers invest outside their farms. But a recent estimate for the U.S.A. claims that there the total non-farming income of farm families is at least two-thirds as large as their total income from farming. This is a remarkable situation, and a very healthy one. Insofar as farmers, especially those who are approaching the limits of technical efficiency, are investing their farm profits elsewhere they are making a special contribution to economic growth by creating new capital and making this available for other sectors of the economy where investment is directed to more profitable lines.

Considerations such as these are not without relevance to the problems posed by mobility both into and out of farming. The reasons for the lack of mobility, especially out of farming, are many and well-known. They are only partly economic, but the economic reasons are powerful. Other reasons, partly social and partly sheerly mystical make it look as if we shall always have too many farmers simply because too many want to be farmers. This is not necessarily a bad thing, for in our crowded urban island it can do little harm to have more people on the land than the rigid sanctions of technical and economic change would decree.

All this is not to say that there is no case for the modernisation of the farms of Britain. Some amalgamations are undoubtedly called for and a great deal of improvement of lay-out could fairly easily be made. Some encouragement to the exit of people from farming can also be designed. But reforms of this kind need not be revolutionary, they can be brought about gradually and almost by stealth.

There is now before Parliament a bill which points the way to some of these reforms. The bill recognises that there are farmers who, however hard they work, cannot hope to get a decent living from their farms at prices which the consumer can afford. It is proposed to offer these farmers help in three ways. First, to enlarge their farms where it is possible for them to get more land. Second, to co-operate with others to obtain the benefits of scale in production and in marketing. Third to re-settle or retire from farming where they want to give up an unrewarding struggle.

Under the National Plan not only is agriculture expected to release labour it is also expected to give up land for other purposes.

The release of land is to be at the rate of 20,000 hectares per year for urban development and 16,000 hectares for forestry. The real significance of this is that it provides a first class illustration of a fundamental change in attitude once one accepts the concept of national as opposed to sectional planning. The emphasis is no longer on what agriculture wants from the rest of the economy. It is on what the rest of the economy wants from agriculture. This change in attitude rejects the 
view that those engaged in an industry are the most competent to decide what its pattern and size should be in the common interest.

There is, finally, another aspect to the kind of planning which we are adopting in Britain. Planning is to proceed not only at the centre but also at the regional level.

Agriculture has a special responsibility here for its activities, even in Britain, still dominate whole geographical regions. Any worthwhile regional planning calls, therefore, for three lines of action. First and foremost it calls for action to improve the infra-structure of the countryside. Secondly, it calls for action to increase the volume and especially the diversity of employment opportunities in country districts so that exit from farming need no longer depend on leaving home and neighbourhood. Finally, it calls for a much more sympathetic understanding by farmers and by countrymen generally of the recreational role which land must play in our crowded industrial civilization.

Given a planned economy with the salient features I have tried to sketch, agriculture is clearly going to need more trained people of many kinds, and a shortage here would constitute a serious handicap to economic growth. Professional expertise will be at a premium at all levels of activity - the dominance of the scientist, the technocrat and the planner can be safely predicted. But professional expertise will not be enough. On the contrary, there is going to be greater need than ever before for wise and informed leadership to guide and co-ordinate the work of the high-powered specialists if agriculture and the community are to gain the maximum "profit" from sinvestment" in their training and equipment. 